\title{
A Review of Application of Risk Management Techniques in Costing and Evaluating Construction Work Projects in Nigeria: A Mathematical Analysis Approach
}

\author{
Sebastian 0 Uremadu ${ }^{1 *}$, Francis Okafor $0^{2}$ and Charity E Duru Uremadu ${ }^{3}$ \\ 1,2Department of Banking and Finance, MOUAU, Nigeria \\ ${ }^{2}$ Department of Banking and Finance, Michael Okpara University of Agriculture, Nigeria \\ ${ }^{3}$ Department of Educational Management, MOUAU, Nigeria
}

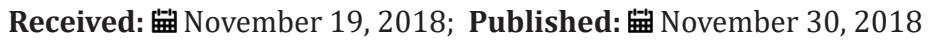

*Corresponding author: Sebastian O Uremadu, Department of Banking and Finance, MOUAU, Umudike, Umuahia, Abia State, Nigeria

\begin{abstract}
There exist some inherent risk elements like physical risk, environmental risk, logistic risk, financial risk, legal risk, political risk, etc. in the construction work environment in Nigeria. Before now those costing these projects use only contingency sum approach and insurance cover without properly taking into consideration all these other critical factors of risk. The result is that most contract projects that border on, construction works were either over-valued or under-valued with their consequent rising cost implications, before execution contract agreement is signed. The present paper used secondary data compiled by a Consultant Quantity Surveyor to carry out some evaluation tests and analysis through the use of an established model that combined material cost (M), labour cost (L) and Plant cost (P) to arrive at a total "best" construction cost estimates (TCCE). That is, TCCE = M+ L + P. Major objectives the paper tried to achieve, are: [1] possibility of using risk management techniques, namely; risk identification, risk analysis and risk response, to ascertain cost variables that could combine to give an optimum cost estimate in order to avoid cost over-runs in construction work project, [2] To ascertain their applicability in Nigerian, in addition to, use of cost effectiveness, cost-benefit analysis and sensitivity analysis (simulation) methods in evaluating and determining the viability of government Projects/Programs in Nigeria. Results from the study confirmed our convictions that it was possible to find total "best" construction cost estimates through an established model that incorporated most key risk factors (variables) inherent in projects as well as use qualitative evaluation techniques to access government project and programs. It is therefore recommended that investors and all stakeholders to construction work project contracts always use a model that captures or incorporates key indicators of risk to arrive at total best construction cost estimates so as to avoid cost over-runs in project execution and outright abandonment.
\end{abstract}

\section{Introduction}

Wherever a construction project is embarked upon, there always exists some risk inherent elements in it, such as physical risk, environmental risk, logistic risk, financial risk, legal risk, political risk and construction risk among other forms of risks that abound in the investment environment the world over. Traditionally, during the pre-contract stage of a project's life most of these risks are not properly identified and quantified in a bid to effectively manage them. Rather, a contingency sum and insurance cover are allowed in order to accommodate the effect of unforeseen circumstances. However, a study by Pouliquen [3], showed that most of these contingency allowances were based on intuitive guesswork and this explains the attendant high cost over-runs involved and or their implications [4].
Moreover, the conventional way in the construction industry is to present construction cost estimates in deterministic terms usually by a single figure, with quantifications, assumptions and exclusions. Pouliquen [3], stated that the single figure could be said to "represent the estimator's assessment of uncertainty", but this would be too vague as there is no means whatsoever of ascertaining the risk that exists as to whether the estimate will be exceeded or bettered and by what proportion. This conventional approach that uses single value estimate has posed a lot of problems in construction projects, especially where public spending is involved. This is because there are frequently cost over-runs to the tune the client is not even expecting and there is no way he could determine the likely increases beforehand since the single value estimate would not reveal the degree of risk in the cost estimate [5]. 
This study thus tries to identify risk inherent variables that could combine to give a total "best" cost estimate for a construction project. The following hypotheses have been put forward for testing:

$\mathrm{H}_{0}$ : It is not possible to use risk management techniques, viz: risk identification, risk analysis (evaluation) and risk response, to ascertain cost variables that could combine to give an optimum cost estimates in a bid to avoid cost over-runs in a construction project.

$\mathrm{H}_{\mathrm{A}}$ : It is possible to use risk management techniques viz: risk identification, risk analysis (evaluation), and risk response, to ascertain cost variables that could combine to give an optimum cost estimates in a bid to avoid cost over-runs in a construction project.

The study will base its findings on the above stated hypothesis to determine the applicability of this concept in risk management projects.

\section{Conceptual Framework}

Most often construction work contracts or projects get stocked or even abandoned due to cost over-runs or inflation over time. When contractors contract work project stakeholders (i.e. promoter and engineers) have failed to capture or build into construction work project contracts costs like inflation and other inherent costs such as foreign exchange rates, etc in the course of time, volatility in exchange rate and inflation might cause costs to complete construction projects to rise astronomically and or in a geometric fashion thereby making it impossible for these projects to get completed or be completely abandoned. Examples abound in Nigeria like the case of Ajaokuta Steel Company, Nigeria National Petroleum Company's refineries in Lagos, Port Harcourt, and Kaduna and others that have been abandoned or stopped because of rising costs which have made execution virtually impossible due lean or scarce resources and non-availability of funds to complete these projects started over 20 years ago and yet remained uncompleted. Same goes to abandoned roads that littered all nocks and crannies of Nigeria [6].

Thus in this study, we shall conceptualise that construction works or projects could get abandoned, uncompleted or stocked mid-way into execution if the executioners (promoter and contractors and engineers) have failed to properly incorporate into the project contract projected costs like inflation, credit risks or exchange rate risks, etc that might crop up in the course of the project execution [4,7]. If these unforeseen costs that are futuristic in outlook have been rightly anticipated (or forecasted) and or captured into the construction work contract phases any event of rising costs chancing out in the course of execution would be taken care of thereby allowing the project execution to go on unhindered. If decision is taken otherwise project could be abandoned due to non-availability of funds to purse the execution of these projects to completion thereby leading to accumulated losses consequent upon huge sums of money already sunk into the project, then abandoned and it has failed with all that have been invested into it. Therefore, the present study advocates incorporation of projected costs or risks that might occur in the course of execution to enable effective completion of projects embarked upon in business firms or Nigerian corporate environment to avoid project abandonment and or risk accumulated costs that could lead to huge losses to corporate firms, in particular, or to the nation, in general as a result of abandoned project occurring. This being due to the non-inclusion of risk management principles or techniques costs while evaluating construction works projects or contracts at both individual firms, corporate companies and/or government levels, so to speak $[4,8]$.

\section{Theoretical Framework Outlook}

Riegel, et al [9], defined risk management as the discovery of existing risks, by observation and imagination, the estimation of the probability and seriousness of these potential losses; the consideration of methods of meeting these risks and the implementation and evaluation of the decisions made. Another authority, Akinkuotu [2], defined risk management as "the act of planning, organizing, directing and controlling of an organisation's assets and activities in ways, which minimize the adverse operational and financial effects of accident losses upon that organisation". The present work agrees with the above definitions of risk management and abstracts from the definitions to say that risk management is a higher 'mental activity, which is better handled by the line managers in an organisation. Nonetheless, Williams Jr. and Henis (1964), in a broad sense, saw risk management as "the minimization of the adverse effects of risk at minimum cost through its identification, measurement, and control".

Risk management is not new, nor does it employ black box magical techniques. It is a system, which aims to identify and quantify all risks to which the business or project is exposed so that a conscious decision can be taken on how to manage these risks. According to, Lockyer and Gordon (1996), risk management is identification and assessment of risks together with the development of strategies to minimize them, and when they do occur, to mitigate any adverse effects or take advantage of beneficial ones. No project plan, according to these joint authors just cited, would be realistic unless account is taken of that which could go wrong, and contingency plans prepared to counteract them. This aspect of project management has been increasingly recognized as one of the most important features of the project manager's task in planning and controlling construction projects in recent limes [5]. Various writers have endeavoured to systematize the process of risk management and establish a generally acceptable terminology. One approach which is common to them and which is suitable for construction risk management is:

a) Risk Identification

b) Risk Analysis/Risk Evaluation and 


\section{c) Risk Response}

Discussions on these stages are primarily concerned with a single project or contract.

\section{Risk Identification}

In order to identify sources of risk, Bannister and Bawcutt [10] suggested the use of general risk profile. The use of such risk profile was found to be helpful in identifying risks associated with construction projects; however, its usefulness may not be easy to make provisional assessment by assigning probability ratings. The reason is that one construction project is quite different and distinct from another, and as such, it is not subject to statistical probability ratings. Various authors are in support of the use of a checklist as a tool in risk identification [4]. One relevant to construction projects are still provided by, Bannister and Bawcutt [10]. They advised that in risk identification, one needs to use a number of alternative checks, to use intuition and to ensure that: any identification is checked carefully by others particularly those who are involved in the day-to-day process that is under examination $[5,6]$.

As a matter of fact, risk identification is important in the during the early stages of appraisal of project it is of direct assistance in establishing project constraints and provides useful data to assist the choice between different projects. Risk identification later provides a basis from which the appropriate organizational structure, tendering procedure, type of contract and risk allocation through the contract document can be formulated. Still, Lockyer and Gordon (1996), opined that the project team and others connected with a project could be encouraged to recognise the potential areas of risk and or beneficial effects by (i) brain storming (ii) using experience and lessons from past project and (iii) using the project network to model possible risk events.

\section{Risk Analysis}

Risk analysis is a means of quantifying risk in order to be amenable to management. The success of risk management hinges on successful risk analysis or risk management. On this, Pouliquen [3], posited that "a successful risk analysis is essentially a method of dealing with the problem of uncertainty" Furthermore, he submitted that uncertainty usually affects most of the variables, which could be combined to obtain a cost estimate and economic rate of return or net present value (NPV) or any of the other indicators, which may be used to evaluate a project. He is also of the opinion that the purpose of risk analysis is to eliminate the need for restricting one's judgement to a single optimistic, or "best" evaluation, by carrying throughout the analysis, a complete judgement on the possible range of each variable and on the likelihood of each variable within this range $[8,10]$.

The common principle behind any technique for the analysis of risk is to allow a range of values to the input data within which the decision maker believes they are likely to lie. An extension of this principle is to try to apply some statistical probability to any values used, so as to weight the possible outcomes to a more likely result $[5,10]$. However, for any construction risks, there is insufficient objective data upon which calculation could be made of the probability of specific outcomes. As such, the result must be dependent on some degree of subjective probability that could be employed $[3,12,13]$.

\section{Risk Analysis Techniques}

Some quantitative techniques for risk analysis have been theoretically established for a number of years but there and applications to construction projects have been limited. Among the techniques commonly used are:

a) Sensitivity Analysis

b) Probability Analysis

c) The Monte Carlo Simulation

d) Decision Tree Analysis

e) Utility Theory

f) Risk Adjusted Discount Rate

g) Decision Analysis

h) Bayescan Theory

i) Stochastic Decision Tree Analysis

Risk adjusted discount rate, sensitivity analysis, the Mante to Carlo Simulation and probability analysis are likely to be used in this study to establish a "best" cost estimate (Lockyer and Gordon, Uremadu and Okafor, 2001)

\section{Risk Response}

Various authors tried to itemise the risk response process in various ways. After a review of various authors, these ones below showed areas found suitable for handling construction risk and are given in terms of:

a) Advance or Reduction

b) Transfer (i.e. Insurance) and

c) Retention or Financing in terms of retention. This view was equally held in Tajudeen [14] and Patel (2000).

\section{A Case Study: Construction of a National Warehouse Silo at Onne, Rivers State for Storage of Grains}

This case study is an attempt to show the application of risk management process in a construction project at the pre-contract stage. The project for the case study is extension of an existing warehouse (Silo) consisting of ground floor with overall size of 
$19.00 \times 47.20$ metres long extreme and 5.20 metres high from ground floor to highest point on the roof level. The warehouse is to be vertically extended to take additional floors. The overall block on completion has three floors including the ground floor [4]. As earlier stated, the starting point in risk management is the "identification of risk". This is followed by 'risk analysis' and it ends with 'risk response'. These three stages are now applied in sequence to the case study thus:

\section{Risk Identification}

With the aid of a checklist as suggested by Bannister and Bawcutt [10] and others, the risk factors identified as regards the project in the case study arc as follows:
a) Adverse Weather,
b) Effects of Fluctuations (i.e inflation rate),
c) Non-availability of Resources.
d) Variation of Construction Work,
e) Variation of Interest Rate,
f) Difficult of construction,
g) Fluctuations in productivity and labour,
h) Inadequate provision of cashflows.

\section{Risk Analysis}

Risk has been said to be measurable. In order to measure risk, some values have to be placed on the risk factors. A convenient method as earlier stated somewhere in this work is to place probabilities on the risk factors [11]. However, because one construction project is unique in its own way and different from others it is not possible to place statistical probabilities or a-priori probabilities on risk factors associated with construction projects, as it is the case with insurance or business risks. In order to quantify the risk factors associated with construction projects therefore, we used subjective probabilities. It should quickly be pointed out here that the placing of subjective probabilities on risk factors should be done by an enlightened and experienced project manager and with some degree of objectivity. It ensures that he draws from his past experience and knowledge on the particular project area of specialization $[4,15]$. In order to effectively quantify the effects of these risk factors on construction cost estimates thereby enabling us to test the hypothesis and or proposition stated at the beginning of this study, three variables were employed in the methodology in gathering data used to conduct the research. These include:
a) Material Cost (M)
b) Labour Cost (L)
c) Plant Cost (P), [8].

\section{Risk Response}

It becomes obvious to both the informed and novice (layman) in the working of construction contracts how the construction cost estimate ranges and the probability of a particular value of construction cost estimate. The client or any other person concerned with risk management can gauge the risk associated with the estimate and thus produce a zone of acceptability [5]. Depending on the management decision and the situation under consideration, any of the risk response approaches could be employed such as avoidance, or reduction, risk retention or transfer, as earlier pointed out in this paper. It is worthy of note here that the sum of money needed to manage the risks involved in the construction project is already incorporated in the analysis [9]. However, it is left to management to decide on a zone or range of acceptability of the construction cost estimate $[15,16]$.

\section{Methodology}

Data from warehouse construction cost projections at Onne, Port Harcourt, Rivers State were used to carry out our main analysis. Major cost variables of (Labour, Material and Plant) will be used to formulate a simple model for "best" construction cost estimate thus:

$$
T C C E=M+L+P
$$

Where; TCCE $=$ Total construction cost estimate

$$
\begin{aligned}
& M=\text { cost of material } \\
& L=\text { cost of labour } \\
& P=\text { cost of plant }
\end{aligned}
$$

This model will be used to estimate total "best" construction cost estimate for the project. Then the Total Revenue Estimate (TRE) for the job will be assumed to be 150 per cent of this total "best" cost estimate, TCCE (as it is normal with most construction projects) having taken into consideration risk inherent in payment delays, time value of money (due to inflation) and cost of-money (i.e. interest rate). Both TCCE and TRE will be subjected to 35 percent risk adjusted discount factor (made up of 5 percent inflation rate plus 30 percent interest on borrowing rate) being mindful of fluctuations prevalent in our economic environment to arrive at or to obtain the Net Present Value (NPV) for the project proper so as to enable us take an objective decision as par the acceptability of the project or otherwise.

Then room will be created for the process to still be subjected to a sensitivity (simulation) analysis by flexing (changing) the value of one of the variables that is easily susceptible to inflationary changes. (This will be repeated using one after another of all other key variables in the model and noting their effects on the overall cost estimate on each occasion). For that consideration, we choose 
cost of material for a 15 percent inflation rate increase in cost. After this is done, the effect on the overall total "best" construction cost estimate (TCCE) will be noted to enable us to take a wellinformed decision on the project's costs. The test will still be tried by assigning a subjective probability values to both TCCE and TRE and then repeat discounting process to arrive at a new net present value (NPV) for this evaluation decision-making. There may still be needing to examine cost-effectiveness and cost-benefit analysis implications of the project, all in a bid to take a scientific decision on the acceptability of the project by all the stake-holders and note their overall effects on the national economy in general $[4,15]$.

\section{Data Presentation and Analysis}

Using the three variables $\mathrm{M}, \mathrm{L}$, and $\mathrm{P}$ that are independent factors that we used in the formulation of our model, the total "best" construction cost estimate (TCCE) prepared by the consultant quality surveyor which we used as a secondary data is broken down as follows:

Sources of Data: From the Consultant Quantity Surveyor (2001)

(Key: $\mathrm{N}=$ Naira, Nigerian Local currency, it was at less than N100/\$1 exchange rate in 2001)

Note that the Equation (1) was used to arrive at the cost value.

The contractor's estimate could be broken down in similar way, by employing probability analysis in quantifying the risks.

\section{Test of Hypothesis}

Ho: It is not possible to use risk management techniques viz: risk identification, risk analysis (evaluation), and risk response, to ascertain cost variables that could combine to give an optimum cost estimate in a bid to avoid cost over-runs in a construction work project.

\section{Computations (I)}

Determining Total Revenue Estimate (TRE) for the Project in a bid to ascertain if it is worthwhile. Evaluation factors used are:

a) Discounted Cashflow Factor (DCF) $=35 \%$ (i.e. $5 \%$ inflation rate $+30 \%$ interest rate)

b) Contractor charges for the job (project) i.e. Revenue Estimate $=150 \%$ of TCCE (i.e. N3,830,000), from Table 1 above.

Table 1: Showing Total "Best" Construction Cost Estimates.

\begin{tabular}{|c|c|}
\hline Cost Variables (Items) & Cost Estimates ( \\
\hline Material Cost(M) & $1,915,000$ \\
\hline Labour Cost (L) & $1,149,000$ \\
\hline Plant Cost (P) & 766,000 \\
\hline $\begin{array}{c}\text { Total "best" construction cost } \\
\text { estimate }\end{array}$ & $\$ 3,830,000$ \\
\hline
\end{tabular}

These data will be used to find the NPV for the project thus:

$$
N P V=(P V \text { of } T R E)-(P V \text { of } T C C E)
$$

Therefore, DCF @ 35\%; we have,

$$
\begin{gathered}
P V \text { of } T R E=150 \% \text { of TCCE } \times \text { DCF @ 35\% } \\
=1.50(3,830,000) \times 0.74074074 \\
=\mathbb{N} 5,745,000 \times 0.7474074 \\
=\mathbb{N} 4,255,555.556
\end{gathered}
$$

Then,

$$
\begin{aligned}
& P V \text { of } T C C E=N 3,830,000 \times 0.74074074 \\
& =\AA 2,837,077.034
\end{aligned}
$$

Therefore, NPV of Project $=(4,255,556.556-2,837,077.034)$

$$
=\mathbb{N} 1,418,518.522
$$

\section{Decision}

Since NPV of Project is positive it is worthwhile. It has also confirmed the possibility of using risk variables to forecast a "best" cost estimate for a construction project.

\section{Computation II}

Applying (i.e. using) a subjective probability of $1 / 5$ (i.e. 0.2 ) that the project will succeed; we will subject our computed values in (1) to this probability and then discount the results to still determine the acceptability of the project.

Hence,

NPV of Project $=($ PV of TRE $x$ 0.2) $)-($ PV of TCCE $x$ 0.2 $)$

$=(T R E x D C F @ 35 \% D C F x 0.2)-(T C C E x D C F @ 35 \%, D C F x O .2)$

$=N 5,745,000(0.74074074 \times 0.2)-N 3,830,000(074074074 \times 0.2)$

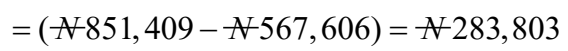

Therefore, $N P V=N 283,803$

\section{Decision}

NPV of Project is still positive. Project has passed through stricter risk test and it is still acceptable.

\section{Sensitivity Analysis Test for the Project}

Sensitivity analysis is a practical way of showing the effect of uncertainty by varying values of the key factors (e.g. price, rate of inflation, net present value, etc) and showing the resulting effect on the project, Luccy (1984) in Uremadu [4]. In the Construction project under study, factors considered critical to the successful operation of this project are costs of material, labour and plant and the net present value. All these cost values depend on the prevalent 
inflation rate. So, considering the after effect of September 11 (2001) terrorists' aeroplane crash in U.S.A. that destroyed both the Pentagon and World Trade Centre (WTC) which it is assumed that the resultant effects have affected world economy drastically, the inflation rate (factor) of 5 per cent we earlier used to adjust 30 percent borrowing rate has now risen to a two-digit rate of 10 percent (Table $2 \& 3$ ). We can use it to carry out the sensitivity analysis evaluation on the project through repeated calculations, but with one variable altered by this known amount and then the sensitivity of the final solution to the changing value of each variable, in turn, is thus found for the management to decide whether the project is worthwhile, given the sensitivity of one or more of the key factors.

Table 2: showing change in cost of labour (L) to arrive at TCCEn.

\begin{tabular}{|c|c|c|}
\hline Item & $\begin{array}{c}\text { Initial value (cost) } \\
\text { estimate }\end{array}$ & $\begin{array}{c}\text { Values when (L) increased by a } \\
\mathbf{1 0 \%} \text { inflation rate. ( })\end{array}$ \\
\hline M & 1915000 & 1915000 \\
\hline L & 1149000 & 1263900 \\
\hline P & 766000 & 766000 \\
\hline TCCE & $\$ 3,830,000$ & $3,944,900$ \\
\hline
\end{tabular}

Table 3: showing change in cost of Plant $(\mathrm{P})$ to arrive at TCCEn.

\begin{tabular}{|c|c|c|}
\hline$\underline{\text { Item }}$ & $\begin{array}{c}\text { Initial value (cost) } \\
\text { estimate }\end{array}$ & $\begin{array}{c}\text { Values when (P) increased by a } \\
10 \% \text { inflation rate. }\end{array}$ \\
\hline$(\mathrm{N})$ & 1915000 & 1915000 \\
\hline M & 1915000 & 1915000 \\
\hline $\mathrm{L}$ & 1149000 & 1149000 \\
\hline $\mathrm{P}$ & 766000 & 841600 \\
\hline TCCE & $3,830,000$ & $3,906,600$ \\
\hline
\end{tabular}

\section{Computations III}

Sensitivity Analysis Test: Applying 10\% inflation rate to cost of material (M) while other key variables remain constant, the new total 'best' construction cost estimate, TCCEn, will be

$$
\begin{gathered}
=30 \%(\text { i.e. borrowing rate })+10 \%(\text { i.e new inflation rate }) \\
=40 \%
\end{gathered}
$$

Therefore,DCFn@40\%1/1.40

Using equation (2)

$$
\begin{aligned}
P V \text { of }(\text { TCCEn }), \quad & =N 4,02 I, 500(0.714285714) \\
& =N 2,872,500
\end{aligned}
$$

Then,

PV of new TRE (ie TREn $), \quad=$ N6,032,250(0.714285.714)

$$
=\mathbb{N} 4,308.750
$$

Therefore, the NPVn $=N P V=(P V$ of TREn $-P V$ of TCCEn $)$
Therefore,

$P V=N 4,308,750-N 2,872,500$

$=\AA 1,436,250$

\section{Computation IV:}

Using 10\% inflation rate to influence initial cost of labour (L) while another critical variable remain constant

Therefore, TCCEn

$$
=T C C E_{2}=N 3,944.900
$$

Then,

$T R E_{n}$

$=150 \%$ of $T C C E$

$=1.50(3.944,900)$

$=\mathbb{N} 5,917,350$

Using equation (2),

PV of TCCE

$$
=3,944,900(0.714285714)
$$$$
=2.817,785.714
$$$$
=N 2,817,785.7
$$

PV of $T R E_{n}$

$=\mathrm{N} 5,917,350(0.714285714)$

$=N 4,226,678,571$

Then, NPV

$=P V$ of $T R E_{n}-P V$ of $T C C E_{n}$

$=281775.7$

And then, $\mathrm{NPV}_{2}$

$=\mathrm{N} 1,408,892.87$

\section{Computation V:}

Using 10\% inflation rate to alter initial cost of plant (L) while other key factors remain constant

$$
\begin{array}{ll}
\text { Therefore, } T C C E_{n}=T C C E_{4} & =N 3,906,600 \\
\text { Then, computing TRE } & =150 \%\left(T C C E_{n}\right) \\
& =1.50(3906600) \\
& =N 5,859,900
\end{array}
$$

Using equation (2),@DCF $=40 \%$

Note,

$N P V_{n}=N P V_{3}$ $=P V$ of $T R E_{n}-P V$ of $T C C E_{n}$

Therefore, $\mathrm{NPV}_{3}=\mathrm{N} 59599000(0.714285714)-\mathrm{N} 3906600$ 
$(0.71428711)$

$$
\begin{aligned}
& =4,185,642.857-2,790,428.571 \\
& =1395214.286
\end{aligned}
$$

Then, $\mathrm{NPV}_{3}$

$=\mathbb{N} 1,395,214.29$

\section{Sensitivity Analysis Results}

Results from the sensitivity analysis we conducted when 10 percent inflation rate was used to influence (affect) key cost variables and the DCF value raised to 40 percent showed the following:

a) There was a positive NPV in all the 3 tests carried out after altering value of critical variables one after another to compute $\mathrm{TCCE}_{\mathrm{n}}$ and $\mathrm{TRE}_{\mathrm{n}}$.

b) However, $\mathrm{NPV}_{\mathrm{n}}$ results revealed a decreasing trend when compared to the original (initial NPV value) computed before using 10 percent to repeatedly sensitise key variables.

c) There was a decreasing trend in value of the $\mathrm{NPV}_{\mathrm{S}}\left(\mathrm{NPV}_{1}\right.$ $=\mathrm{N} 1,436,250 ; \mathrm{NPV}_{2} \mathrm{N1408,892.87}$ and $\mathrm{NPV}=\mathrm{N1,395,214.29}$ ) depending on the initial cost values of the particular key factor being influenced (or changed).

d) Subsequent $\mathrm{NPV}_{\mathrm{S}}$ are tending to negative with the rising trend of the influencing inflationary pressures and depending on the worth (value) of the critical factor being altered (sensitized) and since it was only the the variables and the DCF that were affected by the inflation rate risk of 10 percent, unless until the project managers take into consideration the possibility of equally inflating their $\mathrm{TRE}_{\mathrm{n}}$ charges by a similar or greater rate, they stand to incur a loss in the long-run.

\section{Cost-Effectiveness Analysis Implications of the Project to the Nation based on the TCCE Projections}

Cost - Effectiveness - related to cost-benefit analysis - is used to compare alternatives where it is not possible to value the benefit in money terms, but where it is still possible to quantify the effects of a given expenditure in physical terms [17]. Cost-Effectiveness answers the question: to what extent did the cost achieve the desired and approved objective? Hence, to the project under study, its cost-effectiveness to the financiers can be evaluated as to its likely effect on the people if the Government goes ahead to pay for its execution (i.e. meet the total estimated "best" construction costs). In this regard, if this warehouse (Silo) construction work were executed, Government would be able to store enough grains to feed the Nigerian populace in the oncoming year (2002). (Our evaluation commenced in 2001). Let us project that the number of lives saved from hunger and other associated risks is $1,200,000$. However, if the project is not executed, the nation is likely to experience the kind of inflation it has witnessed since 2000 to date with attendant difficulties (high rate of armed robbery cases/road accidents) leading to loss of lives of a well over 1,800,000 as people transverse the length and breadth of Nigeria in search of food and other means of livelihood. Alternatively if Government decides to divert the fund to build additional roads it will only save 500,000 lives from only motor accidents when compared to 1,200,000 lives saved if this proposed Silo extension project under study is built.

\section{Decision}

Government should embark on the project without much delay. It would definitely pay off. It is cost - effective and the benefits derivable from its construction outweigh costs comparatively showing that it is less risky to embark on the Silo Construction Project.

\section{General Discussion}

From the tests, calculations showed positive NPVs both before and after simulations, and after applying a subjective probability of $(1 / 5)$ or 0.2 resulting in the following values $\$ 1,418,518.527$ and $\mathrm{N283}, 803$, respectively. Also, the outcome of our sensitivity analysis revealed a positive NPV though with a downward trend ending to negative depending on the quantum of the risk variable that is being altered to get the expected results.

\section{Decision}

Since all the tests carried out revealed the possibility of identifying risk variables used to calculate "best" construction Cost Estimate (TCCE) that promises acceptability of the project to both project promoters financiers) and contractors in a bid to avoid either cost over-runs or under-runs. We thus accept our hypothesis that total 'best' construction cost estimate (TCCE) can be projected using some critical risk factors or variables inherent in the project in question. We thus recommend, from results of our study, that unless the contractors rise (increase) their TRE to the tone of 200 percent charges or by an equivalent inflation rate ratio (or percentage) they stand to face the risk of making low revenue (returns) from the project in the years ahead should the observed rising inflationary trends since the September 11,2001 world terrorists' plane crash tragedy continue unabated.

\section{Findings, Conclusion and Recommendations}

It is helpful in decision making using risk management techniques in construction projects to estimate "best" construction costs in order to avoid cost over-runs. The processes employed are; risk identification, risk analysis and risk response. These processes have been long established but have found little use in construction projects. However, the application of this process to a construction project discussed in this study has illustrated a rational and scientific means of managing risks associated with construction project works [4]. The risk management techniques provide a guide to arriving at a construction project's cost over a range of values, 
which it could lie. It also provides the probability of achieving a particular project cost in the range of values as attached. This goes a long way in helping to manage the risk inherent in construction projects in order to avoid cost over-runs [15]. It is suggested, here and now, that risk - analysis be carried out at the initial stage of a project's life in order to ascertain beforehand [18], the type of risk response to employ. This helps management save time and money as well as social-economic consequences inherent in public project execution. The above remarks are our convictions and conclusions.

\section{References}

1. AA Raheem, Co Quantity Surveyors, Suite 20 Via Nipost Building, Area 10 Abuja.

2. Akinkuottu SB (1987) Concept of Risk Management Daily Times. Lagos.

3. Pouliquen LY (1970) Risk Analysis in Project Appraisal (World Bank Staff Occasional Paper No. 11), London and Baltimore Hopkins University Press.

4. Uremadu SO, Okafor FO (2001) Application of risk management techniques in costing and evaluating construction work project. Journal of Research and Development in Africa. 1 (1) p. 1-9.

5. Lock D (1992) Project Management, $5^{\text {th }}$ edition, England: Gower Publishing.

6. Morris C (1992) Quantitative Approaches in Business Studies, 2 ${ }^{\text {nd }}$ edition, Singapore: Pitman publishing.

7. Anyanwu UN (2014) Credit Risk and Economic Growth in Nigeria Evidence from commercial Banks, A proposal presented to the Department of Banking and Finance, COLMAS in partial fulfilment for the award of Master (MSc) in finance MOUAU.
8. Malevergne Y, Sornette D (2006) Extreme Financial Risks; from Dependence to Risk Management, The Netherlands: Springer.

9. Ricgel R (1976) Insurance Principles and Practice, (Property and Liability) Englewood Cliffs NJ Prentice Hall, Inc.

10. Bannister JE, Bawcutt PA (1981) Practical Risk Management London Witherby and Co. Ltd Lockyer, K. and Gordon J (1996) Project Management Network Techniques; London E \& FN Spons.

11. Gaalitz (1995) Financial Engineering: Tools and Techniques to Manage Financial Risk, FT London: Pitman Publishing Ltd.

12. Rejda GE (2008) Principles of Risk Management and Insurance, Boston; Pearson Education, Inc.

13. Okafor PO (1983) Investment Decisions: Evaluation of Projects and Securities. England; Casscll Limited.

14. Tajudeen RA (2001) Risk Management in Construction Work. A Term Paper presented in Partial Fulfilment for the Course PRT712; Risk Management, Department of Project Management, FUTO, Owerri, Imo State.

15. Patel BM (2000) Project Management: Strategic Financial Planning Evaluation and Control. India: Vikas Publishing PVT Ltd.

16. Jorion P (2007) How information are Value at Risk Disclosure Prvine, USA: University of California.

17. Umeh JA (1977) Feasibility and Viability Appraisal, Ibadan Onibonqje Publishers. Uremadu, S.O. (1999) Basic Insurance Principles, Abuja: Hisbi Grace Publishers Company. Uremadu SO (2001) Risk for Project Managers. Benin: Mindex Publishing Co Ltd.

18. William J, Arthur C, Heins RM (1964) Risk Management and Insurance, New York: McGraw Hall Book Company.

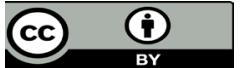

This work is licensed under Creative Commons Attribution 4.0 License

To Submit Your Article Click Here:

Submit Article

DOI: $10.32474 /$ CIACR.2018.05.000216

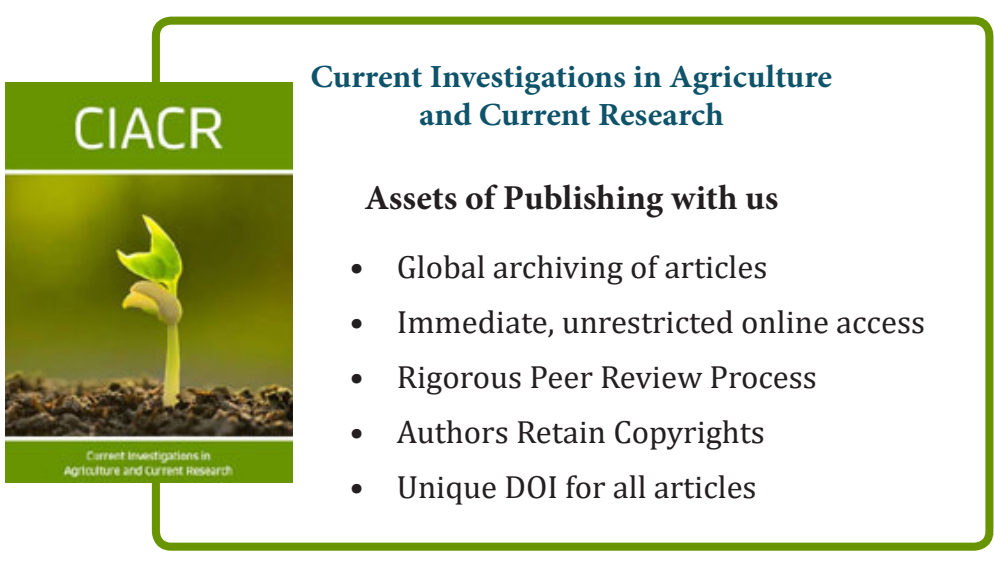

